Portland State University

PDXScholar

7-8-1996

\title{
Comparison of Two Phonological Treatment Procedures for a Child with Phonological Deviations
}

Katherine Vaughan Kemper

Portland State University

Follow this and additional works at: https://pdxscholar.library.pdx.edu/open_access_etds

Part of the Speech and Rhetorical Studies Commons

Let us know how access to this document benefits you.

\section{Recommended Citation}

Kemper, Katherine Vaughan, "Comparison of Two Phonological Treatment Procedures for a Child with Phonological Deviations" (1996). Dissertations and Theses. Paper 5284.

https://doi.org/10.15760/etd.7157

This Thesis is brought to you for free and open access. It has been accepted for inclusion in Dissertations and Theses by an authorized administrator of PDXScholar. Please contact us if we can make this document more accessible: pdxscholar@pdx.edu. 


\section{THESIS APPROVAL}

The abstract and thesis of Katherine Vaughan Kemper for the Master of Science in Speech Communication: Speech and Hearing Sciences were presented July 8,1996 , and accepted by the thesis committee and the department.

COMMITTEE APPROVALS:
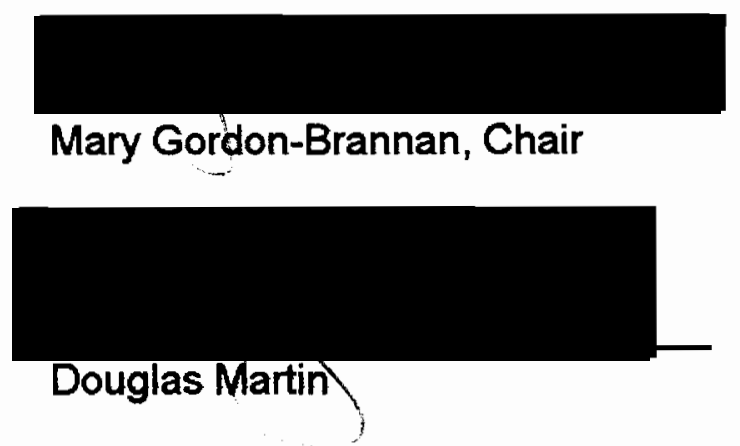

DEPARTMENT APPROVAL:
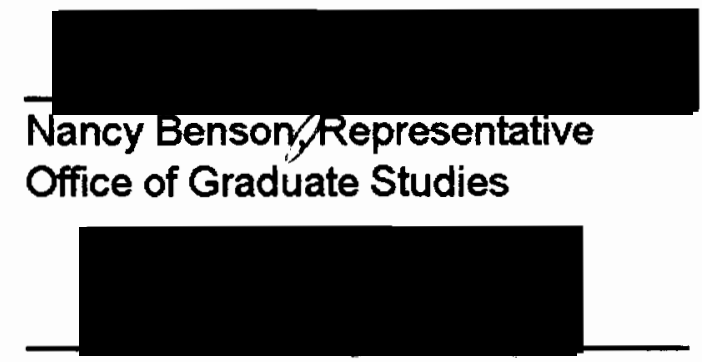

Rhea Paul, Acting Chair

Department of Speech Communication

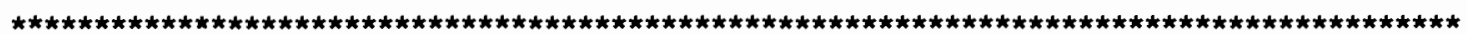

ACCEPTED FOR PORTLAND STATE UNIVERSITY BY THE LIBRARY

by

on 20 Lecpued 1996 


\section{ABSTRACT}

An abstract for the thesis of Katherine Vaughan Kemper for the Master of Science in Speech Communication: Speech and Hearing Sciences presented July 8, 1996.

Title: Comparison of Two Phonological Treatment Procedures for a Child with Phonological Deviations

Choosing an effective and efficient phonological treatment approach is an important decision for clinicians when treating children with phonological deviations. Current research supports the effectiveness of phonological treatment, but few studies have compared two approaches. More comparative studies are essential to support clinical intervention for children who are highly unintelligible.

This single-subject study was designed to compare the effectiveness of two phonologically-based treatment approaches in facilitating an intelligible speech production system for one highly unintelligible preschool female. Multiple baselines across behaviors with an alternating treatment design were used in this descriptive study. This study sought to answer the following questions: (a) Is there a clinically significant difference between the effectiveness of the cycling approach and the minimal pairs approach in treating a child with phonological disorders? and (b) Do the phonological cycling and/or the minimal pairs treatment approaches result in generalization of treated sounds in a targeted pattern to untrained words containing the treated sounds 
and to untreated sounds/sound contexts in the same phonological pattern?

Using the phonological assessment instrument, the APP-R in conjunction with the CAPD, four phonological deviations were chosen for phonological remediation. Two deviations were assigned to the phonological cycling approach (Hodson \& Paden, 1991) and two to the minimal pairs approach (Blache, 1989; Fokes, 1982). Remediation alternated between the two approaches every 6 sessions, beginning with the cycling approach, for a total of 24 sessions. Treated sounds from each targeted deviation were taught and reassessed using the APP-R to compare treatment effectiveness. To examine generalization of targeted phonological patterns to phonemes in other contexts, periodic probes of treated sounds within untrained words and untreated sounds/sound contexts in the same pattern were administered.

Results of the CAPD indicate that both treatment methods were effective in improving some of the treated phonological deviations for this subject though neither method was more effective than the other. Probe words indicated generalization to untrained words and untreated sounds/sound contexts in some phonological patterns. These findings support the phonologically-based theory of remediation: the goal of phonological treatment is developing a whole phonological system, rather than perfecting targeted deviations. 
COMPARISON OF TWO PHONOLOGICAL TREATMENT PROCEDURES

FOR A CHILD WITH PHONOLOGICAL DEVIATIONS

by

KATHERINE VAUGHAN KEMPER

A thesis submitted in partial fulfillment of the

requirements for the degree of

\author{
MASTER OF SCIENCE \\ in \\ SPEECH COMMUNICATION: \\ SPEECH AND HEARING SCIENCES
}

Portland State University

1996 


\section{ACKNOWLEDGMENTS}

First I would like to thank my daughter, Sarah, for waiting patiently for her mother to finish college and for growing into a sweet child full of love, enthusiasm, and funny jokes.

Second, I would like to thank the faculty in Portland State's Speech and Hearing Department for teaching and preparing me for my future profession as a speech-language pathologist. I also appreciate the time and excellent recommendations Doug Martin and Nancy Benson offered as members on my thesis committee. I am especially grateful to my academic and thesis advisor, Mary Gordon-Brannan, whose wise and intelligent counsel guided me through the entire thesis .

Last, thank you to all the students in the speech and hearing program who were always helpful and kind. I would especially like to thank my great friend, Karen Ware, whom I greatly admire and respect. Thank you for listening, advising, and caring. 


\section{TABLE OF CONTENTS}

PAGE

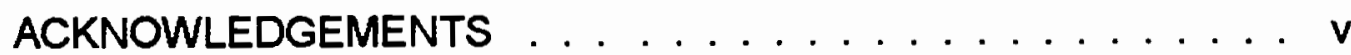

LIST OF TABLES . . . . . . . . . . . . . . viii

CHAPTER

I INTRODUCTION ............... 1

Statement of Purpose $\ldots \ldots \ldots . \ldots 3$

Definition of Terms . . . . . . . . . . 4

II REVIEW OF THE LITERATURE . . . . . . . . . . . 7

Traditional Articulation Perspective . . . . . . . 7

Linguistic Perspective . . . . . . . . . . 8

Phonological Cycling Approach

Distinctive-Feature Treatment

Comparative Studies

Single-Subject Research Design . . . . . . . . 19

Summary . . . . . . . . . . . . . 22

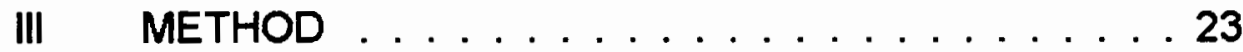

Subject $\ldots \ldots \ldots \ldots \ldots \ldots$

Instruments . . . . . . . . . . 25 
Procedures . . . . . . . . . . . . 27

Pre- and Posttest Measures

Treatment Target Selection

Baselines and Probes

Treatment Procedures

Data Analysis . . . . . . . . . . . . . . 37

IV RESULTS AND DISCUSSION . . . . . . . . . 38

Results ................. . 38

Course of Treatment

Treatment Effectiveness Results

Generalization Results

Discussion . . . . . . . . . . . . . 49

Treatment Effectiveness

Treatment Generalization

Experimental Control

Summary

v SUMMARY AND IMPLICATIONS . . . . . . . . 62

Summary. . . . . . . . . . . 62

Implications .............. 64

Clinical Implications . . . . . . . . 64

Research Implications . . . . . . . . . 65

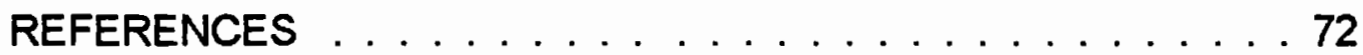

APPENDIXES
A Informed Consent Form . . . . . . . . 72
B List of Training Words and Probe Words . . . . . . 73 


\section{LIST OF TABLES}

TABLE

PAGE

1 Pretest Phonological Analysis Summary (APP-R) . . . 26

2 Treatment Schedule . . . . . . . . . . . . . . 31

3 Movement From Perceptual Awareness to Carryover

in Minimal Pairs Approach . . . . . . . . . . 35

4 Results of Contrasting Pairs Treatment for

Postvocalic Consonants . . . . . . . . . . . 42

5 Results of Contrasting Pairs Treatment for Liquid /r/ . . . 44

6 Summary and Analysis of APP-R Results . . . . . . . 46

7 Results of Probing for Generalization . . . . . . . . . . 48 


\section{CHAPTER I}

\section{INTRODUCTION}

For most people, communicating is a natural phenomenon, occurring without effort, and developing naturally. Infants communicate by crying and cooing. Older babies babble while toddlers begin to use meaningful words. As toddlers grow into preschoolers, listeners expect more. They are no longer content with interpreting babble and unintelligible words. What happens to the $2 \%$ to $8 \%$ of these young children when their speech is disordered (Secord, 1989)? These children become confused and do not understand why we misinterpret their messages (Paul, 1995). Some become frustrated or angry. Early referral to a speech-language pathologist (SLP) is critical to help these children catch up to their normally developing peers. For remediation to be effective, SLPs must choose the most appropriate treatment approach. This can be a difficult decision considering the number of treatment approaches found in the literature that arise from different philosophies, goals, and procedures (Weiss, Gordon, \& Lillywhite, 1987). SLPs may base their decision on experience but when they also review the published research on these treatment approaches, their choices are more valid.

In reviewing the literature, SLPs find two prominent treatment perspectives: the traditional approach and the phonological approach. 
Traditional treatment of speech disorders utilizes the phonemic approach for children with multiple articulation errors where each individual speech sound is treated until perfected (Weiss et al., 1987). This approach was prevalent until the mid-1970s when many researchers and clinicians began viewing misarticulations from a phonological perspective, rather than from an articulation perspective (Ingram, 1982). From the phonological perspective, speech deviations are viewed in terms of patterns of speech sounds instead of individual speech sounds. These speech deviations are systematic sound errors affecting entire classes of sounds or sound sequences and are labeled phonological deviations or phonological processes. Children produce these patterns of speech errors by altering or simplifying sounds and producing them differently than the adult standard articulation (Hodson \& Paden, 1991). In a normally developing child, most phonological deviations are resolved without intervention between the ages of $11 / 2$ and 4 years as the child acquires adult sound patterns (Ingram, 1989). When these adult patterns do not emerge, intervention by a SLP facilitates the emergence of adult patterns by identifying a child's phonological deviations and eliminating them in phonological remediation (Hodson \& Paden, 1991). Remediation can be maximized through generalization of treated phonological skills to other members of the same phonological pattern (Tyler, Edwards, \& Saxman, 1987). When phonological patterns generalize, direct treatment of every phoneme is not necessary.

Research in phonological intervention over the past 25 years has led many SLPS and researchers to reconsider their perspective on treating children 
with multiple articulations and to acknowledge that articulation errors can be seen as patterns of errors, not just as single sound errors. Two of the most widely-used phonological remediation methods are the phonological cycling approach and the minimal pairs approach. Hodson and Paden (1991) developed a phonological cycling approach for children with highly unintelligible speech where systematic patterns in a speech sample are identified as deviant and are selected for remediation based on developmental and clinical research findings. In the minimal pairs approach, remediation focuses on an absent feature (e.g., a placement error) that is treated using progressive approximation to reach specific criterion based on norms found in the research (Blache, 1989).

Current research supports the effectiveness of both treatment approaches (Blache, Parsons, \& Humphreys, 1981; Elbert \& Gierut, 1986; Gordon-Brannan, Hodson, \& Wynne, 1992; Hodson, 1982; Saben \& Ingham, 1991; Tyler \& Sandoval, 1994; Weiner, 1981), but few studies have compared both phonological treatment approaches to determine if one approach is more effective than the other (Royer, 1995; Tyler et al., 1987). Choosing between the two phonological treatment approaches is difficult for clinicians without adequate support in research studies. More comparative studies are essential to support clinical intervention for children with phonological deviations.

\section{Statement of Purpose}

To begin to fill the need for comparative research, this study compared the effectiveness of phonological cycling and minimal pairs approaches to 
determine if there was a difference between these two approaches when treating a child with phonological deviations using a single-subject alternating treatment design. The primary research question was: Is there a clinically significant difference between the effectiveness of the cycling approach and the minimal pairs approach in treating a child with phonological disorders? The corresponding hypothesis was: There is a clinically significant difference between the effectiveness of the cycling approach and the minimal pairs approach in treating a child with phonological disorders. A secondary question was: Do the phonological cycling and/or the minimal pairs treatment approaches result in generalization of treated sounds in a targeted pattern to untrained words containing the treated sounds and to untreated sounds/sound contexts in the same phonological pattern? The corresponding hypothesis was: Generalization of treated sounds in a targeted pattern to untrained words containing the treated sounds and to untreated sounds/sound contexts in the same phonological pattern occurs when treating a child with phonological disorders using the phonological cycling and/or the minimal pairs treatment approaches.

\section{Definition of Terms}

The following are definitions of terms used in this study and are derived from Hodson and Paden (1991):

Articulation. The motor movements of the articulators during speech production. 
Backing. An anterior phoneme, frequently alveolars, is replaced with a back phoneme, usually velars, e.g., /ku/ for two.

Consonant sequence omission. One or more sound segments from two or more contiguous consonants are omitted, e.g., /e/ or /pe/ for play.

Distinctive feature. A characteristic of a phoneme describing manner, place, or voicing.

Fronting. A velar $/ \mathrm{k}, \mathrm{g}, \eta /$ or glottal $/ \mathrm{h} / \mathrm{phoneme}$ is replaced with an alveolar phoneme /d, t, z, s, n, l/, e.g., /ti/ for key.

Glide deviation. A glide phoneme $/ j, w /$ is omitted or substituted by a nonglide phoneme, e.g., /ve/ for way.

Liquid /// deviation. The /// phoneme is omitted or substituted by another phoneme, e.g., /jif/ for leaf.

Liquid / $/$ / deviation. The $/ r /$ phoneme is omitted or substituted by another phoneme, e.g., /wen/ for rain.

Nasal deviation. A nasal phoneme $/ m, n, \eta /$ is omitted or substituted by a nonnasal phoneme, e.g., /do/ for no.

Phoneme. A group of similar speech sounds that are perceived as belonging to the same sound category. Each phoneme consists of a set of distinctive features.

Phonological deviation. A regularly occurring modification of the standard adult speech pattern that usually simplifies syllable structures or phoneme classes.

Phonological patterns. A description of the way a grouping of speech 
sounds, such as a sound class, consonant sequence, or syllable shape are produced that can be either deviant or standard speech patterns.

Phonology. The speech sound system of a language, including how speech sounds are classified, organized, and produced.

Postrocalic singleton omission. The final singleton consonant in a syllable is omitted, e.g., / $/ \mathrm{ko} /$ for coat.

Prevocalic singleton omission. The initial singleton consonant in a syllable is omitted, e.g., /ot/ for coat.

Stopping. A stop phoneme $/ b, d, g, p, t, k /$ is substituted for a nonstop phoneme, e.g., /ti/ for see.

Strident deviation. A strident phoneme /f, v, s, z, S, $3,5,5, \mathrm{dg} /$ is omitted or substituted by a nonstrident phoneme, e.g., /tef/ for safe.

Syllable reduction. One or more syllables are omitted, e.g., /nænæe/ for banana.

Velar deviation. A velar phoneme $/ k, g, \eta /$ is omitted or substituted by a nonvelar phoneme, e.g., /tot/ for coat.

Weak syllable deletion. The unstressed syllable is deleted, e.g., /we/ for away. This is one type of syllable reduction. 


\section{CHAPTER ॥}

\section{REVIEW OF THE LITERATURE}

In developing remediation programs for children with speech disorders, SLPs consider various philosophies or theories that form the basis of their treatment approach. The two most widely-known theories of speech disorders are the traditional articulatory perspective and the more contemporary linguistic perspective (Secord, 1989).

\section{Traditional Articulation Perspective}

Beginning in the 1920s, articulation intervention emphasized listening and speech production exercises (Secord, 1989). In this traditional approach to treatment, one single speech sound is targeted at a time. Treatment for a new sound is initiated only when the misarticulated sound is mastered. Emphasis is placed on learning how to perceive and say individual sounds accurately by properly positioning the articulators. Currently, some clinicians continue to advocate articulation treatment and choose among the many procedural variations that have evolved over the years (Weiss et al., 1987). Other clinicians retain traditional articulation treatment for only their clients with mild and moderate severity levels (Secord, 1989). 


\section{Linguistic Perspective}

The influence of linguistic conceptions emerged in the 1970s, when linguists suggested that severe articulation disorders have an underlying linguistic deficit. They believe that speech errors are systematic, patterned, and based on phonological principles (Secord, 1989). Linguistic approaches to phonological treatment are based on the assumption that a child needs to learn the phonological rules that represent phonemes and how these phonemes can be combined into meaningful words considered acceptable in an adult's speech pattern (Creaghead, 1989). Instead of isolating phonemes, several sounds are treated together resulting in a more efficient remediation.

The goals of phonological treatment are to modify the child's rule system toward the adult standard and to establish an improved system for communication (Creaghead, 1989). These goals are accomplished when patterns identified as deviant are suppressed during phonological remediation by teaching phonological rules. A primary advantage of teaching phonological rules is the child may generalize and correct several phonemes at the same time. Linguistically based treatment can be categorized into two major approaches: the phonological cycling approach and the distinctive features approach.

\section{Phonological Cycling Approach}

Hodson and Paden (1991) developed the phonological cycling approach for children with highly unintelligible speech where systematic patterns in a 
speech sample are identified as deviant using the Assessment of Phonological Processes - Revised (APP-R; Hodson, 1986). Their approach to the systematic nature of speech deviations was developed from Compton's (1970) report that children with speech sound disorders have phonological systems that are delayed, but are similar versions of typically developing speech. Deviant patterns are prioritized for each individual child using developmental and clinical research findings and considering the child's stimulability and readiness for the target patterns. Remediation focuses on target patterns that gradually emerge to facilitate an intelligible speech sound system (Ingram, 1989).

All phonological cycling remediation sessions, as described by Hodson and Paden (1991), begin and end with auditory stimulation to develop auditory awareness of the target sound. Using slight amplification, the clinician reads 12-15 words containing the target sound for 1 to 2 minutes. The child listens without repeating because children with highly unintelligible speech do not always hear their own errors. After this auditory bombardment, other types of stimulation such as tactile and visual cues are used to increase awareness of the target patterns. Clinicians can use tactile cues with /s/blends, for example, by sliding a finger down a child's arm while saying /s/and lightly tapping the hand when the $/ t /$ is released for the /st/ blend. Visual stimulation can provide additional cues such as telling the child to watch the clinician's mouth or tongue. Visual and tactile cues facilitate initial learning and are faded as the child learns the words. After phonological patterns are introduced, production practice of targeted patterns is incorporated into play activities found to be efficient and 
motivating for children. Modeling and cueing are faded as the child's production improves. From the beginning of treatment, children are active participants in their learning in order to maintain their learning outside of the clinic. Active involvement also assists in generalization if the child is given time to gradually acquire a standard phonological system. Direct treatment of every phoneme is not necessary because children, especially young children, often generalize treated phonological skills to untreated phonemes in the target pattern (Hodson \& Paden, 1991).

Instead of using criterion levels to analyze mastery, phonological patterns are targeted during cycles or time periods. Cycles allow children to learn targeted patterns gradually. Generally, a cycle includes 2 to 6 hours of intervention for each target pattern (e.g., velars) and 60 minutes for each targeted phoneme within the targeted pattern (e.g., word-initial /k). After Cycle I, reassessment using Hodson's (1986) APP-R determines which target patterns need to be recycled in Cycle II. According to Hodson and Paden (1991), children usually require two or three cycles, with a maximum of five cycles to become intelligible, but there is considerable variability because of children's individualism.

Hodson (1982) described the effect of the cycling approach on intelligibility for 125 children, ages 3 to 9 years. All subjects were assessed to be highly unintelligible as determined by the Assessment of Phonological Processes (APP) (Hodson, 1980). Auditory bombardment was provided for 2 minutes at the beginning and end of each session. The subjects then drew 
picture cards of targeted words used for production practice during various play activities. All of the 70 subjects who completed the program emerged intelligible over a period ranging from 3 to 18 months of remediation. Results indicated that by targeting phonological deviations over two or three cycles, the cycling approach was both effective and efficient for these subjects, but it is unknown as to what part individual maturation played in the improvement.

Gordon-Brannan et al. (1992) successfully implemented a phonological cycles approach for a 4-year-old child with a mild hearing impairment who was previously treated at age 2:7 using a traditional articulation approach. After 16 months of targeting two or three consonants per semester, the subject's intelligibility showed minimal improvement in spontaneous speech from his pretest score of $6 \%$. At age 4:6, the APP-R pretest revealed a severe phonological deviation score and his informal conversation was rated as $18 \%$ intelligible by familiar listeners. The phonological cycling approach was implemented using six cycles over a 2-year period. Posttest at age 6:5 and again at 3 months posttreatment revealed that his phonological deviation score improved from a severity level of severe to mild while his intelligibility was rated by familiar listeners as $98 \%$ and unfamiliar listeners as $89 \%$.

Using a modified cycling approach, Tyler and Sandoval (1994) treated 6 children aged 3:6 to 4:8 with moderate-to-severe disorders in both language and phonology. Subjects were treated individually during 45-minute sessions, 2 to 3 times a week for 12 weeks. In each of the two cycles, one to three deviant patterns were targeted for 2 weeks. Each pattern included two target sounds. 
Intervention was based on a perception-production/minimal pairs approach. Subjects who received direct phonological intervention showed a moderate decrease in phonological deviations while the subjects who received only language intervention demonstrated negligible improvement in deviations. Subjects who received both language and phonological intervention exhibited an almost complete suppression of targeted deviations. In this study, the most effective and efficient treatment included both language and phonological intervention.

\section{Distinctive-Feature Treatment}

Interest in distinctive features began in the 1950s with the work of Jakobson who designed binary feature systems to describe the sounds in language (Creaghead, 1989). In the binary system, each phoneme is described by the presence or absence of articulatory and acoustic distinctive features. Limitations of this system were described by Walsh (1974) who believed the system is an appropriate model of language proposed by linguists, but may not be useful in describing children's patterns of errors. A more useful system is based on the traditional parameters of manner, place, and voicing where the type of articulation errors is described in terms of features (Creaghead, 1989).

Features are component parts of each speech sound and they describe consonants by their manner of production, place of articulation, and condition of voicing. For example, substituting $/ t /$ for $/ s /(t / s)$ indicates an error of manner, $t / k$ is an error of place, and $p / b$ is a voicing error. Manner of production refers to the 
way the vocal tract modifies the air stream. For example, the sound is a stop when the tract is closed, a fricative when the constriction is narrow, an affricate when stops are followed by a fricative release, a nasal when the velum drops to produce nasal resonance, and a lateral when air passes around a narrowed tongue (Creaghead, 1989). Place of articulation refers to those parts of the speech mechanism involved in the production of the sound. For example, $/ t /$ is described as a lingua-alveolar sound because the tongue touches the alveolar ridge. Voicing describes consonants that either use phonation such as $/ \mathrm{b} /$ and $/ \mathrm{m} /$ (voiced sounds) or do not use phonation such as $/ \mathrm{p} /$ and $/ \mathrm{t} /$ (voiceless sounds). Vowels can be described by the shape of the oral cavity and the position of the tongue, lips, and pharynx while the vocal tract remains relatively open. In addition to these physical features, sounds have a linguistic function to make words different in meaning, according to linguistic theory (Blache, 1989). Distinctive features, thus, are components of phonemes that discriminate meaning.

Distinctive feature approaches are based on a feature analysis that shows which features are absent or present in the child's phonological system. The goal of treatment is to teach children to include the absent features in their own rule system by isolating and teaching a single sound property (feature), rather than teaching phonemes as a whole (Blache, 1989). Instead of concentrating on one sound, Blache recommended concentration on the features of one phonemic property at a time (e.g., voicing). Minimal word pairs are used for stimulating new sound properties. These word pairs are two 
phonetically equivalent words that differ by a single sound property. Examples are big and pig that differ only with voicing in the initial consonant. Word pairs must also differ in meaning and be from the child's lexicon.

Remediation proposed by Blache (1989) is a form of progressive approximation where reinforcement is provided for small articulatory changes that move toward the target phoneme. Blache's program includes four steps: discussion of words to ensure the child understands the word, auditory discrimination of the distinctive feature to test the child's perception, production training to shape the behavior, and carryover training to produce longer utterances and to move the sessions outside of the clinic. Blache preferred to call his approach a stimulation program rather than a training program because it provides a context in which learning can occur instead of teaching sound production.

Variations of the distinctive feature approach were described by Elbert and Gierut (1986). In one variation, minimal pairs are used to contrast target consonants with the null. For example, a child who omits word-initial consonants could benefit from contrasting the target word pin with in . In another approach, minimal pairs that represent maximal opposition are used to help the child see the full range of sound possibilities. For example, when a child omits final consonants, training with two final consonant words (e.g., lame and lake) instead of only one (e.g., lay and lake), provides the child with another way of remediating deviant patterns. Word pairs can also be "near minimal pairs" where the vowel adjacent to the target sound is the same, but another 
sound differs (e.g., toe and soap).

Fokes (1982) suggested that in the minimal pairs treatment approach, any contrasting pairs, not simply minimally paired contrasts, can be used. The choice of contrasts depends upon the nature of the problem. If a child's system contains few sounds, maximal contrasts may initially be an appropriate approach. Phonemic contrasts may be presented by comparing word pairs with sound differences in the initial or final position of words. Vowel contrasts can even be presented. According to Fokes, most deviant patterns can be treated using variations of contrasting pairs as long as they provide oppositions in speech as well as semantic contrasts. Contrasts are defined in terms of the difference in the meaning of the words and that a sound brings about this difference.

Weiner (1981) examined the effects of a minimal pairs treatment method by teaching phonological oppositions to two children, ages $4: 10$ and $4: 4$, with unintelligible speech. The purposes of this study were to determine if this approach was effective in reducing phonological deviations and if generalization occurred to untreated words. Phonological deviations selected for treatment were final consonant deletion, stopping, and word-initial fronting. Using a multiresponse baseline, treatment items consisted of five repetitions each of the four target words within each minimal pair for a total of 20 target words per deviation. Baseline measurements for target patterns were obtained at pretest. After two treatment trials of the $\mathbf{2 0}$ words, target patterns were measured again until the pattern was less than $50 \%$ of the subject's responses to target words. 
Generalization to nontreated words was also evaluated by eliciting delayed imitation responses to generalization probes of $\mathbf{2 4}$ words for each target pattern. Subject A's deviations were totally suppressed after 6 sessions, while Subject B's deviations fell below $50 \%$ after 14 sessions. Generalization to untreated words occurred for both subjects. These results indicate that, for these subjects, the minimal pairs approach was effective and efficient in reducing target patterns and in generalizing treatment effects to untreated words.

In their 1981 study, Blache et al. examined both the effectiveness of the minimal pairs approach on substitution errors and the generalization to untrained feature classes using a distinctive feature matrix. Subjects included 7 children aged 5:4 to 6:7 who demonstrated four or more sound errors. After assessment, all subjects were assigned to one sound pair (tense/lax, continued/interrupted, grave/acute, strident/mellow, or compact/diffuse). Feature categories were designed to describe all phonemes using a combination of articulatory and acoustic features. For example, the prevocalic tense sound $/ \mathrm{p} /$, that is produced with a relatively greater degree of muscle tension, was paired with the lax sound, /b/ by training with the words pig/big; the postvocalic interrupted sound $/ t$, where the airstream is completely blocked at some point during production, was paired with the continued sound, $/ \mathrm{s} /$, with the training words night/nice; and the postvocalic strident sound /s/, where noise is produced by forcing the airstream through a small opening, was paired the mellow sound, $|\theta|$, with training words mouse/mouth. Remediation included practicing three minimal word pairs that contained the target feature until $90 \%$ 
criterion was reached. Posttest results indicated a significant reduction in substitution errors (73\%) and a moderate reduction in untrained words that contained the target feature (30\%). For these subjects, minimal pairs treatment was effective in reducing substitutions errors and in generalizing to untrained words.

Saben and Ingham (1991) investigated whether minimal pairs treatment would be effective in reducing deviations if they omitted all direct motoric training, that is, without models, phonetic placement cues, or extensive motor practice. The investigators also examined the generalization of treatment effects to untreated phonemes in the targeted phonological deviation. There were 2 subjects in this study who exhibited multiple speech-sound errors. Each subject was assigned one phonological deviation as follows: Subject 1, age 4:4, targeted stopping of fricatives in the final position and Subject 2, age 3:9, targeted final consonant deletion of fricatives. Remediation included a programmed instruction format with criterion levels established for movement to the next level. Neither subject was able to pass criterion at the independent production level until auditory models were provided. The authors, therefore, were unable to describe the effectiveness of the linguistic-based phonemic aspects of minimal pairs treatment without mentioning the phonetic contribution. Treatment goals were met after $91 / 2$ months and $41 / 2$ months for Subjects 1 and 2, respectively. Generalization did not occur to untreated words or phonemes. For these subjects, minimal pairs was effective, but not efficient in reducing target deviations. 


\section{Comparative Studies}

Most of the studies on treatment approaches have investigated either the cycling or the minimal pairs approach. This author found only two studies in the literature that compared both phonological treatment approaches to determine their effectiveness in remediating children with phonological deviations and the generalization effect of treatment to untrained sounds in the same phonological pattern (Royer, 1995; Tyler et al., 1987).

Tyler et al. (1987) compared the phonological cycling and the minimal pairs approaches to determine their effectiveness in treatment and generalization. Subjects for their study included 4 children, aged 3:1 to 5:1, who exhibited a moderate to severe phonological disorder that significantly affected their intelligibility. Remediation phases included pretreatment, treatment (12 - 16 sessions), and follow-up. Progress was measured with generalization probes administered prior to treatment for each targeted deviation and periodically during treatment. Subjects $A$ and $B$ were trained using the perception-production/minimal-pairs approach including perception, word imitation, independent naming, production of minimal pairs, and sentences. Both subjects were assigned one target deviation each. Subjects $C$ and $D$ were trained using a modified cycles procedure that included perception and production training. The cycles approach was modified by eliminating amplification during auditory bombardment and defining a cycle as 3 weeks. Both subjects were assigned three to five target deviations. Results indicated that both procedures were effective in facilitating the suppression of targeted 
phonological deviations in a relatively short period of time ( $21 / 2$ months) and generalization occurred to untrained sounds. For these subjects, both treatment approaches were effective and efficient.

Another comparative was an unpublished thesis by Royer (1995) whose single-subject study was designed to compare the effectiveness of the phonological cycling and minimal pairs treatment approaches with a male, age 4:6, who presented with a profound phonological severity level according to the APP-R. Two deviant patterns were treated using the cycling approach and two were treated using the minimal pairs approach. Remediation occurred three times a week over 8 weeks during which treatment approaches were alternated every 2 weeks. Results of the APP-R indicated minimal changes between preand posttest scores for all target phonological patterns. Probes indicated generalization to targeted and non-targeted words occurred for only one (consonant sequences/stridents) of the four target patterns. For this subject, neither treatment approach was effective.

\section{Single-Subject Research Design}

While group designs are more common, McReynolds and Kearns (1982) stated that single-subject designs are gaining popularity in both clinical psychology and in special education. Specifically, single-subject designs are used in behavioral research for determining which factors improve performance. In speech-language pathology, researchers want to know which factors will alter a targeted communication disorder and can be implemented in an intervention 
program. Results from single-subject designs can be directly applied to treatment of children, offering accountability to clients and third party funding agencies. This accountability is further justified when SLPs match clients with similar subjects in single-subject studies and use the study as the basis for their intervention program. According to the authors, it is easier to match clients in single-subject studies than with group designs. Kazdin (1982) suggested that single-subject designs can help bridge the gap between research and clinical practice when these research studies produce clinically significant results.

McReynolds and Thompson (1986) cited technical and practical advantages of single-subject experimental designs over group designs. Technically, single-subject designs allow the researcher to examine cause-andeffect relationships between an independent variable (treatment) and a dependent variable (targeted communication goal) by establishing control over the treatment procedures to ensure that the treatment alone was responsible for improving behavior. Without this experimental control, it is difficult to rule out extraneous variables such as maturation, time, or nonclinical environments (e.g., home or school) that could improve speech disorders. When these variables can not be ruled out, it is difficult to state that the treatment alone improved the speech disorder. Making erroneous conclusions could result in unnecessary treatment or choosing the less effective and efficient treatment program. Control in a group study is done by examining trends over time and using control groups that do not offer clear cause-and-effect relationships for the 
individual. The second technical advantage of single-subject designs is the ability to examine intersubject variability by duplicating the design on other subjects and analyzing reasons for variability among the subjects. This variability is difficult to accomplish with group studies who may report "statistically significant improvement" even though some subjects did not improve. The last technical advantage is being able to examine the intrasubject variability by studying the subject's behavior over time and measuring the targeted behavior repeatedly. Observing this variability in group studies is more difficult when behaviors are measured only two times (before and after treatment) or when multiple measurements are averaged together.

A practical advantage of single-subject designs cited by the authors occurs when clinicians do their own research and develop intervention programs based on their results. If this is done during their regular clinic hours, time and expenses are saved. Group studies involve more time to recruit clients, design the study, and perform statistical analysis.

According to Hegde (1987), multiple baselines can demonstrate experimental control of a subject's variability in single-subject designs by observing and measuring a number of behaviors prior to treatment, during treatment, and again at posttest. If the baselines of treated behaviors improve while untreated behaviors remain the same, there is strong evidence for experimental control. Barlow and Hersen (1984) suggested that control in multiple-baseline designs can be even stronger if there are a minimum of three or four baselines that are as independent as possible. 
For single-subject studies that compare two treatment approaches, Hegde (1987) described the alternating treatments design that determines the relative effects of two or more treatments. Counterbalancing the order of treatment minimizes the order effect by randomly changing the time of day clinic occurs, alternating clinicians, or changing the clinic setting. When an order effect occurs, treatment effects could be explained on the basis of the specific order. Counterbalancing also minimizes the carry-over effect where generalization of the first treatment carries over to the second treatment.

\section{Summary}

Children with multiple misarticulations benefit from phonologically-based remediation, including the minimal pairs and the phonological cycling approaches. Both approaches facilitate the emergence of phonological patterns by changing the deviant patterns instead of treating each sound error. Choosing between these two phonological approaches is difficult for clinicians without adequate support in research studies. This research project utilized a multiple baseline single-subject design to compare the effectiveness and generalization of two phonological treatment approaches, phonological cycling and minimal pairs, to determine if there is a clinically significant difference between these approaches when treating a child with phonological deviations. 


\section{CHAPTER III}

\section{METHOD}

In this single-subject study, the effectiveness of the phonological cycling approach (Hodson \& Paden, 1991) and the minimal pairs approach (Blache, 1989; Fokes 1982) was compared by administering both treatment approaches to one preschool child who was highly unintelligible. Targeted deviations to facilitate the development of an intelligible system were determined using the results from Hodson's (1986) Assessment of Phonological Processes - Revised (APP-R) analyzed by the Computer Analysis of Phonological Deviations (CAPD; Hodson, 1992). Treated sounds from each targeted deviation were taught and measured again at posttest to determine progress. Generalization of treated deviations to phonemes in other contexts was measured using periodic probes of treated sounds within untrained words and untreated sounds/sound contexts in the same pattern. Multiple baselines across behaviors with an alternating treatment design were used in this descriptive study.

\section{Subject}

The female subject selected for this study was referred from a Portland SLP engaged in private practice. The subject exhibited a profound phonological disorder of unknown origin and met the following criteria necessary for inclusion 
in this investigation:

1. The parent or guardian of the child will sign a release form allowing the child to participate in the study (Appendix A).

2. The subject will be between 3 and 5 years of age.

3. The subject will pass a bilateral pure tone hearing screening at $20 \mathrm{~dB}$ $\mathrm{HL}$ for the frequencies of $500,1000,2000$, and $4000 \mathrm{~Hz}$.

4. The subject will score within normal limits on the Preschool Language Scale-3 (PLS-3; Zimmerman, Steiner, \& Pond, 1992).

5. The child will have no history of mental or neurological impairment according to the parent or guardian and investigator observation.

6. The child's phonological severity level will be severe or profound as measured by the APP-R analyzed by the CAPD.

7. The child will have five or more phonological deviations that occur with a frequency of $40 \%$ or more ( $70 \%$ or more for glides) as measured by the APP-R.

8. The child will have had no previous articulation or phonological intervention.

At pretest, the subject of this study was a 3 year, 4 month old female who exhibited highly unintelligible speech. She passed the hearing screening at 20 $\mathrm{dB} \mathrm{HL}$ for the frequencies of $500,1000,2000$, and $4000 \mathrm{~Hz}$ and received an expressive raw score of 34 (standard score of 114) and an auditory comprehension raw score of 35 (standard score of 109) on the PLS-3. This placed the subject in the $82 \mathrm{nd}$ and 73 rd percentile, respectively, which is within normal limits for receptive and expressive language. The private SLP who referred the subject confirmed these language results and agreed with the 
parents and the investigator that there was no evidence of mental or neurological impairment. The subject had no prior treatment for articulation or phonological deviations and the parent agreed to bring the subject to Portland State University's Speech and Hearing Clinic for 24 sessions.

The APP-R was administered to the subject prior to treatment and resulted in an average phonological deviations percentage of 62 and a phonological deviancy score of 62 which equates to a severity rating of profound. As seen in Table 1, the percentage of occurrence for all pattern deviations analyzed by CAPD indicated the following deviation patterns were over $40 \%$ : postvocalic singletons, consonant sequences, stridents, velars, liquid $/ /$, liquid $/ r /$, and glides (over $70 \%$ ).

\section{Instruments}

The APP-R is a phonological assessment instrument that elicits single word productions for analysis of phonological deviations. All American English phonemes are assessed, including 34 consonant sequences. Results of the APP-R are entered into the CAPD program on an IBM compatible computer that analyzes the subject's productions and determines a severity level, an average phonological deviation score, and percentage of occurrences for the deviant patterns of syllable reduction, prevocalic singleton omission, postvocalic singleton omission, consonant sequence omission, strident deviation, velar deviation, liquid /// deviation, liquid /r/ deviation, nasal deviation, and glide deviation. Backing is analyzed and considered severe if there are 5 or more 
Table 1

Pretest Phonological Analysis Summary (APP-R)

Pattern deviations Percentage of occurrence

Syllable reduction

Prevocalic singletons

Postrocalic singletons

Consonant sequences

Stridents

Velars

Liquid //

Liquid $/ r /$

Nasals

Glides
21

20

74

105

65

86

82

52

26

90

Note. The lower the percentage of occurrence, the closer the deviation is to normal. 
occurrences of the 10 selected opportunities. The CAPD also lists phonological patterns to be targeted that occur in $40 \%$ or more ( $70 \%$ or more for glides) of the possible opportunities. While validity and reliability studies have not been conducted for the APP-R and CAPD, both instruments are widely used by practicing SLPs around the country.

\section{Procedures}

\section{Pre- and Posttest Measures}

The APP-R was administered to identify the subject's phonological deviations, to select target patterns for remediation, and to determine progress of deviant patterns. The APP-R was administered three times: (a) before treatment began (pretest measure), (b) halfway through the study (midway measure), and (c) at the end of the study (posttest measure).

Common objects, pictures, and body parts were used to elicit 50 spontaneous utterances from the subject according to the APP-R instructions. When the response was not the target word or there was no response, a delayed or direct model was provided. Targeted responses were phonetically transcribed on the APP-R form and input into the CAPD computer program to analyze the subject's phonological deviations.

During administration of the APP-R, the subject's responses were tape recorded to be used later to establish interrater reliability. A Portland State University speech-language pathology graduate student independently listened to the audiotapes and phonetically transcribed the subject's productions. When 
there were differences between the graduate student and this researcher, both listeners reviewed the audiotapes together until $100 \%$ agreement was reached (Connell \& McReynolds, 1988).

\section{Treatment Target Selection}

From the pretest CAPD list of recommended pattern deviations (postvocalic singletons, consonant sequences, stridents, velars, liquid $/ /$, liquid $/ r /$, and glides), the most frequently occurring deviations were chosen for this study: postvocalic singleton omissions, consonant sequence omissions, strident deviations, velar deviations, liquid // deviations, and glide deviations. Liquid / $/$ / was not chosen to minimize the carry-over effect between liquid $/ /$ and liquid / $/$ / (McReynolds \& Kearns, 1982). However, when stimulability probes indicated that the subject was unable to produce $/ \mathrm{k} / \mathrm{or} / \mathrm{g} /$ in any position, liquid /r/ deviations replaced velar deviations as a targeted patterns. Consonant sequences and stridents were grouped together and treated simultaneously as recommended by Hodson and Paden (1991).

In making the assignments of the deviant patterns to treatment approaches, normative developmental data and recommendations from Hodson and Paden (1991) and Blache (1989) were considered. Placing similar patterns into separate treatment approaches was also considered to strengthen the experimental control (Barlow and Hersen, 1984). Thus, consonant sequences/stridents and postvocalic consonants were assigned to different approaches because they are both early to middle developing omission 
patterns. Similarly, liquids $/ \mathrm{r} /$ and $/ / /$ were separated because they are both later developing sounds. In order to follow Hodson and Paden's procedures for treating consonant sequences/stridents, this deviant pattern was chosen for the cycling approach. The liquids were randomly assigned. Consonant sequences/stridents and liquid $/ / /$ were assigned to the cycling approach while postvocalic singletons and liquid $/ r /$ were assigned to the minimal pairs approach. Glides and velars were measured, but remained untreated serving as control patterns to provide evidence that the treatment was responsible for improving the subject's phonological system and not extraneous variables such as maturation or the home environment (Hegde, 1987).

\section{Baselines and Probes}

Multiple baselines across behaviors were used in this study to measure treatment effectiveness and to demonstrate experimental control. Baseline measurements were determined at pretest using the APP-R for the four targeted patterns (liquid $/ /$, consonant sequences/stridents, postvocalic singletons, and liquid / $/$ /) and the two control patterns (glides and velars). These six baseline measurements were the pretreatment occurrence patterns that were compared to subsequent assessments. It was expected that the treated patterns would improve while untreated patterns would remain at baseline.

Probes were used to determine the generalization effect of treatment. The following terms were used to describe the use of probes in this study:

1. A targeted pattern is the phonological pattern being treated including liquid $/ / /$, consonant sequences/stridents, postvocalic singletons, and liquid $/ r$ /. 
2. A treated sound is the sound (e.g., initial ///) in the targeted pattern (e.g., liquid $/ /$ ) being treated in the context of five predetermined words (e.g., leaf).

3. An untrained word includes the treated sound (e.g., initial ///) in three predetermined words not used in treatment (e.g., lion).

4. An untreated sound includes a sound/sound context (e.g., // blend) in the targeted pattern (e.g., liquid ///) that is not used in treatment in the context of three predetermined words (e.g., flag).

It was expected that by treating a sound in a targeted pattern, generalization would occur both within context (i.e., to untrained words) and across context (i.e., to untreated sounds/sound contexts). Table 2 displays targeted patterns, treated sounds, and untreated sounds/sound contexts.

Probes were administered at pre- and posttest and every 2 weeks by eliciting three untrained words and three words with untreated sounds/sound contexts for each of the four targeted phonological patterns. Generalization was measured by eliciting single-word productions using objects or pictures.

\section{Treatment Procedures}

The subject participated in 60-minute phonologically-based intervention sessions three times a week for 8 weeks as displayed in Table 2. During the first 2 weeks, two deviant patterns (consonant sequences/stridents and liquid II) were targeted using the phonological cycling approach by treating liquid /// the first week and consonant sequences/stridents the second week. In the next 2 weeks (weeks 3 and 4), one different pattern (postvocalic singletons) was targeted using the minimal pairs treatment approach. In weeks 5 and 6 , the 
Table 2

Treatment Schedule

Week Session Approach Targeted pattern Treated sounds Untreated sounds

\begin{tabular}{|c|c|c|c|c|c|}
\hline 1 & $\begin{array}{l}1 \\
2 \\
3\end{array}$ & Cycling & Liquid /// & $\begin{array}{l}\text { Initial /// } \\
\text { Medial /// } \\
\text { Initial /pl/ }\end{array}$ & Initial /fl/ \\
\hline 2 & $\begin{array}{l}4 \\
5 \\
6\end{array}$ & Cycling & $\begin{array}{l}\text { Consonant } \\
\text { sequences/ } \\
\text { stridents }\end{array}$ & $\begin{array}{l}\text { Initial /sp/ } \\
\text { Initial /st/ } \\
\text { Initial /sm/ }\end{array}$ & Initial /sw/ \\
\hline 3 & $\begin{array}{l}7 \\
8 \\
9\end{array}$ & $\begin{array}{l}\text { Minimal } \\
\text { pairs }\end{array}$ & $\begin{array}{l}\text { Postvocalic } \\
\text { singletons }\end{array}$ & $\begin{array}{l}\text { Final } / t \\
\text { Final } / d / \\
\text { Final } / \mathrm{m} /\end{array}$ & Final $/ n /$ \\
\hline 4 & $\begin{array}{l}10 \\
11 \\
12\end{array}$ & $\begin{array}{l}\text { Minimal } \\
\text { pairs }\end{array}$ & $\begin{array}{l}\text { Postvocalic } \\
\text { singletons }\end{array}$ & $\begin{array}{l}\text { Final } / \mathrm{t} / \\
\text { Final } / \mathrm{d} / \\
\text { Final } / \mathrm{m} /\end{array}$ & Final $/ \mathrm{n} /$ \\
\hline 5 & $\begin{array}{l}13 \\
14 \\
15\end{array}$ & Cycling & Liquid /// & $\begin{array}{l}\text { Initial/medial /// } \\
\text { Initial /bl/ } \\
\text { Initial /pl, bl/ }\end{array}$ & Initial /fl/ \\
\hline 6 & $\begin{array}{l}16 \\
17 \\
18\end{array}$ & Cycling & $\begin{array}{l}\text { Consonant } \\
\text { sequences/ } \\
\text { stridents }\end{array}$ & $\begin{array}{l}\text { Initial /sp, st/ } \\
\text { Initial /sn/ } \\
\text { Final /-ts, -ps/ }\end{array}$ & Initial /sw/ \\
\hline 7 & $\begin{array}{l}19 \\
20 \\
21\end{array}$ & $\begin{array}{l}\text { Minimal } \\
\text { pairs }\end{array}$ & Liquid /r/ & $\begin{array}{l}\text { Initial } / r \text { / } \\
\text { Final } / r \text { / }\end{array}$ & Medial / $/$ / \\
\hline 8 & $\begin{array}{l}22 \\
23 \\
24\end{array}$ & $\begin{array}{l}\text { Minimal } \\
\text { pairs }\end{array}$ & Liquid /r/ & $\begin{array}{l}\text { Initial /r/ } \\
\text { Final /r/ } \\
\text { Initial /tr/ }\end{array}$ & Medial / $r /$ \\
\hline
\end{tabular}


cycling approach was repeated using the original two targeted patterns (liquid $\mathrm{N} /$ and consonant sequences/stridents) in Cycle 2 as recommended by Hodson and Paden (1991). In the final 2 weeks (weeks 7 and 8), a fourth pattern (liquid /r/) was treated using the minimal pairs approach. For each of the four targeted patterns, three treated sounds were selected to create a list of targeted (training) words that were used during remediation (Appendix B).

Phonological Cycling Approach. Treatment procedures for the phonological cycling approach followed Hodson and Paden's (1991) methods. Each session included the following six steps: (a) review of previous words, (b) auditory bombardment, (c) probe for current words, (d) production-practice, (e) probe words for next session, and (f) auditory bombardment.

After reviewing words used in the prior session, amplified auditory stimulation was provided for 1 minute by reading 15 words containing treated sounds for the current session. Amplification was provided by using a Radio Shack Stereo Amplified Listener (Model NOVA-35). After this auditory bombardment of listening words, the subject repeated words from a different list of potential production-practice words. Five words that were easily elicited were chosen for the current session's practice. The subject glued pictures representing the words on index cards for use during various production practice activities. Auditory and/or visual cues were provided only when necessary. Each session ended with stimulability probes of potential words for the next session, followed by the amplified auditory stimulation using the same listening words from the beginning of the session. During the cycling approach, 
a home program was recommended to the parents by providing them with a copy of the current listening words to be read to the subject once a day. The current production-practice cards were also sent home for the subject to name during a 2-minute daily review with a parent.

Minimal Pairs Approach. Treatment procedures for the minimal pairs approach followed recommendations by Blache (1989) and Fokes (1982). Following the recommendation that phonemic contrasting can be presented through any type of contrasting pairs, as long as both semantic and articulatory contrasts are presented, contrasting pairs were chosen for this subject that were already present in the subject's lexicon (Fokes, 1982). Following guidelines by Blache (1989) for establishing treatment levels, each treated sound progressed through the following six levels: (a) discussion, (b) perceptual awareness, (c) imitation, (d) production training, (e) independent naming, and (f) carryover training.

Discussion involved showing the subject pictures that represented contrasting words and asking questions to determine if the words were in her linguistic vocabulary. For example, when targeting postvocalic consonants using the treated sound of final $/ t /$, pictures of boat and bow were presented with questions such as "Which one do you put in your hair?" and "Which one floats in the water?" If the subject did not understand the words, they were eliminated. Once understanding was verified, the subject progressed to the next level to examine her perceptual awareness of the targeted distinctive feature. This was accomplished by instructing the subject to listen to the word being said 
and correctly pointing to one of two pictures. This researcher randomly repeated the two words until $100 \%$ accuracy was achieved on seven consecutive trials. After perceptual awareness was determined for the first set of pictures, another set (hat/hay) was presented by repeating the first two steps (discussion and perceptual awareness) until there were three sets of pictures (e.g., boat/bow, hat/hay, and nut/knee) for the treated sound (e.g., final /t). See Table 3 for an example of movement from perceptual awareness to carryover for postvocalic consonants.

When all three contrasting pairs reached criterion for perceptual awareness, the subject progressed to the imitation level for final $/ t /$ where she produced the three contrasting pairs prompted by this investigator's model until $90 \%$ accuracy was reached in 20 trials. After criterion for imitation was reached for final $/ t$, the first three steps (discussion, perceptual awareness, and imitation) were repeated two times, once for final $/ \mathrm{d} /$ and again for final $/ \mathrm{m} /$ as displayed in Table 3 (Fokes, 1982). In tracking productions, correct responses were those that included the targeted feature, even if the sound was incorrect. For example, a response of boap for boat was considered correct when targeting postvocalic singletons (Blache, 1989).

After successful imitation, a home program was introduced to the parents by sending home the current picture cards and teaching them how to model the contrasting pairs during a 2 minute daily review. The parents were instructed to listen to the subject's imitation, praise good productions, and report the results at the next session. Incorrect productions were not corrected by the parent. 
Table 3

Movement From Perceptual Awareness to Carryover in Minimal Pairs Approach

\begin{tabular}{|c|c|c|c|}
\hline Sounda & Pairs b & Levels & Criterion for movement \\
\hline Final /t & $\begin{array}{l}\text { First } \\
\text { Second } \\
\text { Third } \\
\text { All three }\end{array}$ & $\begin{array}{l}\text { Perceptual awareness } \\
\text { Perceptual awareness } \\
\text { Perceptual awareness } \\
\text { Imitation }\end{array}$ & $\begin{array}{c}100 \% \text { accuracy in } 7 \text { trials } \\
100 \% \text { accuracy in } 7 \text { trials } \\
100 \% \text { accuracy in } 7 \text { trials } \\
90 \% \text { accuracy } 20 \text { trials }\end{array}$ \\
\hline Final /d/ & $\begin{array}{l}\text { First } \\
\text { Second } \\
\text { Third } \\
\text { All three }\end{array}$ & $\begin{array}{l}\text { Perceptual awareness } \\
\text { Perceptual awareness } \\
\text { Perceptual awareness } \\
\text { Imitation }\end{array}$ & $\begin{array}{c}100 \% \text { accuracy in } 7 \text { trials } \\
100 \% \text { accuracy in } 7 \text { trials } \\
100 \% \text { accuracy in } 7 \text { trials } \\
90 \% \text { accuracy } 20 \text { trials }\end{array}$ \\
\hline Final $/ \mathrm{m} /$ & $\begin{array}{l}\text { First } \\
\text { Second } \\
\text { Third } \\
\text { All three }\end{array}$ & $\begin{array}{l}\text { Perceptual awareness } \\
\text { Perceptual awareness } \\
\text { Perceptual awareness } \\
\text { Imitation }\end{array}$ & $\begin{array}{c}100 \% \text { accuracy in } 7 \text { trials } \\
100 \% \text { accuracy in } 7 \text { trials } \\
100 \% \text { accuracy in } 7 \text { trials } \\
90 \% \text { accuracy } 20 \text { trials }\end{array}$ \\
\hline \multirow[t]{2}{*}{$\begin{array}{l}\text { Final } \\
t, d, m /\end{array}$} & All nine & $\begin{array}{l}\text { Production training } \\
\text { Independent naming }\end{array}$ & $\begin{array}{l}90 \% \text { accuracy } 20 \text { trials } \\
90 \% \text { accuracy } 20 \text { trials }\end{array}$ \\
\hline & & Carryover stages $c$ & $90 \%$ accuracy 20 trials \\
\hline
\end{tabular}

Note. This example is for postvocalic consonants. aSound is the treated sound.

${ }^{b}$ Each treated sound has 3 contrasting pairs. ${ }^{c}$ Criterion for each of the 6 stages. 
When the subject reached criterion for imitation for all three treated sounds (final $/ t, d, m /$ ), remediation progressed to the next level, production training, by demonstrating her use and control of the feature using the nine contrasting pairs (Table 3). During this step, the subject was presented with two contrasting pictures (e.g., boat and bow) and was instructed to be the "teacher." When the subject said one of the two words, this investigator pointed to the picture produced. When the subject said bow when she meant boat, she was assisted in producing the correct production. At this time, this investigator explained that when the subject said bow instead of boat, she was not communicating what she intended, thus, omitting final consonants communicated a different word to the listener than was planned. Production training, including traditional cues for articulatory placement and contextual cues, continued until the subject was $90 \%$ accurate for 20 trials.

After production training, the subject progressed to the independent naming level where she produced the nine contrasting pairs without a model during various games and activities until she reached $90 \%$ accuracy in 20 trials. Once independent naming began in the clinic, home practice also became unmodeled. At the next level, carryover training began by gradually increasing the length of the utterance. Each of the following stages of the carryover treated must reach $90 \%$ accuracy for 20 trials before moving to the next carryover stage: a + word, the + word, 3-word utterances, 4-word phrases, sentences, and creating stories with the minimal pairs (Table 3). 
Data Analysis

In this study, the effectiveness of the phonological cycling and minimal pairs treatment approaches were compared to determine if there was a clinically significant difference between the two approaches. Multiple baselines across behaviors of targeted and untargeted control patterns were compared at pretest, mid-treatment, and posttest to measure treatment effectiveness and to demonstrate experimental control. Probes of untrained words and untreated sounds/sound contexts were compared to determine the generalization effect of treatment.

Results obtained from the baseline behaviors and generalization probes were analyzed descriptively and displayed in tables. Percentage of change for each pattern was determined by dividing the amount of change between preand posttest APP-R results by the pretest percentage of occurrence. The percentage of correct probe words for each pattern was determined by dividing the number of correct productions by the total possible probes presented for each pattern. 


\title{
CHAPTER IV
}

\section{RESULTS AND DISCUSSION}

\author{
Results
}

The primary purpose of this study was to compare the effectiveness of the cycling approach with the minimal pairs approach to investigate if there was a clinically significant difference between the two approaches in treating a child presenting with phonological disorders. The secondary purpose was to investigate if phonologically-based treatment results in generalization of treated sounds in a targeted pattern to untrained words containing the treated sounds and to untreated sounds/sound contexts in the same phonological pattern. To test these hypotheses, multiple baselines with an alternating treatment design and generalization probes were used in this study for a single subject who received remediation for profound phonological deviations. Preliminary to presenting results for the two hypotheses, the course of the two treatment approaches will be described.

\section{Course of Treatment}

The female subject, aged 3:4, participated in 24 sessions of 
phonologically-based intervention with the treatment methods of phonological cycling and minimal pairs approaches being alternated every six sessions.

Three sounds/sound contexts were selected for each of the four targeted deviant patterns (see Table 2 for targeted patterns and treated sounds).

\section{Phonological Cycling}

The subject received 4 weeks of treatment for two deviant patterns, liquid $\mathrm{N} /$ and consonant sequences/stridents, using the phonological cycling treatment approach as described by Hodson and Paden (1991). Each deviant pattern was targeted for three sessions. One training sound was targeted at each session by practicing five words containing the treated sound/sound context. Rather than targeting a pattern until reaching a criterion level as was done in the minimal pairs approach, the subject practiced words during play activities within a cycle that was defined as 2 weeks. Instead of counting the number of productions, the subject produced as many correct responses as possible during each session.

Liquid //. Remediation for liquid /// occurred during weeks 1 and 5 using five targeted words for each treated sound. At each session, one target sound context was practiced. For Cycle I (week 1), five initial /// words were practiced in session 1, five medial /// words in session 2, and five initial /pl/ words in session 3. In Cycle ll (week 5), five initial and medial /// words were practiced in session 13, five initial /bl/ words in session 14 , and five initial /pl/ and /bl/ words in session 15. 
Consonant sequences/stridents. Consonant sequences/stridents were treated during weeks 2 and 6 . As with liquid $/ /$, one target sound was practiced during each session, that is, for Cycle I (week 2), five initial /sp/ words were practiced during session 4, five initial /st/ words in session 5, and five initial /sm/ words in session 6. In Cycle II (week 6), five initial /sp/ and /st/ words were practiced in session 16, five initial /sn/ words in session 17, and five final/-ts/ and /-ps/ words in session 18.

\section{Minimal Pairs}

The subject also received 4 weeks of treatment for two different deviant patterns, postvocalic consonants and liquid /r/, using the minimal pairs approach as described by Blache (1989) and using contrasting pairs, rather than minimal pairs, as described by Fokes (1982). For each targeted pattern, three treated sounds were chosen. For each treated sound, five targeted words were chosen. Instead of practicing one sound per day as with the cycling approach, each treated sound was practiced until criterion was reached. (See Table 3 for criterion requirements.).

Of the six sounds treated with contrasting pairs, three reached criterion for independent naming (final $/ t$, initial $/ r /$, and final $/ r /$ ). In general, both targeted deviations progressed at the same pace through the imitation steps, but liquid $/ r /$, especially final $/ r /$, moved to higher levels in less time than postvocalic consonants.

Postvocalic Singletons. Remediation for postvocalic singletons occurred 
during weeks 3 and 4 . Each targeted word that contained the deviant feature, the final consonant, was matched with a similar word that omitted the targeted feature. For example, to eliminate the subject's omission of the postvocalic singleton, final $/ t$, the word boat was matched with the word bow.

Final consonant word pairs were practiced at one level until they reached criterion to progress to the next level (see Table 4 for results of postvocalic consonants remediation). All treated sounds reached criterion for perceptual awareness, production training, and imitation after 2 days of phoneme training. Final $/ t /$ reached criterion for the next level, independent naming, on the fifth day of training though final $/ \mathrm{d} /$ and final $/ \mathrm{m} / \mathrm{did}$ not reach criterion. Remediation for final / $/$ then progressed to the next level, carryover training, although criterion was never reached and therefore did not progress to the final level, carryover training. On the last day of treatment for postvocalic consonants, percentage of accuracy at the carryover level for final $/ t /$ was $70 \%$ while percentages at the independent naming level for final $/ \mathrm{d} /$ and final $/ \mathrm{m} /$ were $50 \%$ and $40 \%$, respectively.

Liquid / $/$ /. Remediation for liquid $/ r /$ occurred during weeks 7 and 8 . As with postvocalic singletons, each targeted word was matched with another word that was similar. For example, to eliminate the subject's deviation of using the glide $/ w /$ for $/ r /$, the word rock was matched with the word walk.

Liquid / $r$ / word pairs were practiced at one level until they reached criterion to progress to the next level. Initial $/ r /$ and final $/ r /$ reached criterion for perceptual awareness, production training, and imitation after 2 days of 
Table 4

Results of Contrasting Pairs Treatment for Postvocalic Consonants

Session subject reached criterion

Levels (criterion for movement) Final $/ \mathrm{t} /$ Final $/ \mathrm{d} / \mathrm{Final} / \mathrm{m} /$

Perceptual awareness $(100 \%$ in 3 trials)

1

2

3

Production training (90\% in 10 trials)

1

2

3

Imitation (90\% in 20 trials)

2

3

4

Independent naming (90\% in 20 trials)

5

Carryover training ( $90 \%$ in 20 trials)

Note. There were a total of six sessions in which criterion could be reached. No session number was recorded when criterion was not reached. 
phoneme training while initial /tr/ required 3 days of training (see Table 5 for results of liquid /r/ remediation). Initial/tr/ did not reach criterion for independent naming although initial / $/$ / and final $/ r /$ reached criterion on the fourth day of training. Remediation then progressed to carryover training although criterion was not reached at this level and did not progress to the carryover training level. On the last day of treatment for liquid / $r$ /, percentage of accuracy at the carryover level for initial $/ r /$ was $55 \%$ and $75 \%$ for final $/ r /$ while initial $/ \mathrm{tr} /$ reached $40 \%$ at the independent naming level.

\section{Treatment Effectiveness Results}

Treatment effectiveness was measured in this descriptive study by using multiple baselines across behaviors with an alternating treatment design to answer the primary research question: Is there a clinically significant difference between the effectiveness of the cycling approach and the minimal pairs approach in treating a child with phonological disorders? Phonological deviation measurements were taken at pretest, half way through the study, and at posttest to compare percentage of occurrence for the four targeted patterns (liquid $/ /$, consonant sequences/stridents, postvocalic singletons, and liquid /r/) and the two control patterns (glides and velars).

The percent of change between the pre- and posttest scores indicated that three of the four targeted patterns improved. Specifically, improvements were noted for postvocalic singletons $(8 \%)$, consonant sequences/stridents 
Table 5

Results of Contrasting Pairs Treatment for Liquid / $/$ /

\section{Session subject reached criterion}

Levels (criterion for movement) Initial /r/ Final / $r$ Initial / $r$ /

Perceptual awareness (100\% in 3 trials)

1

2

3

Production training ( $90 \%$ in 10 trials)

1

2

4

Imitation (90\% in 20 trials)

2

3

5

Independent naming (90\% in 20 trials)

4

4

Carryover training ( $90 \%$ in 20 trials)

Note. There were a total of six sessions in which criterion could be reached. No session number was recorded when criterion was not reached. 
(14\% and $25 \%$, respectively), and liquid $/ r /(17 \%)$ as displayed in Table 6.

Results for the fourth targeted pattern, liquid ///, indicated no improvement at posttest. Posttest results of the control patterns showed that glides improved by $78 \%$ while the usage of velars worsened by $-14 \%$. The average phonological deviation score for all pattern deviations improved at the midway measure and at posttest by $19 \%$. The severity interval improved from profound to severe at the midway measure where it remained at posttest. It should be noted that all target patterns were occurring over $40 \%$ on the posttest APP-R.

In comparing pre-and posttest results between treatment methods, target patterns showed clinically significant improvement for both approaches.

Deviations treated by the cycling approach improved for consonant sequences/stridents (14\%/25\%), although liquid $/ /$ showed no improvement. Deviations treated by the minimal pairs approach improved for both postvocalic singletons (8\%) and for liquid $/ r /(17 \%)$.

\section{Generalization Results}

The generalization effect of treatment was measured by eliciting probe words from the subject to answer the secondary research question: Do the phonological cycling and/or the minimal pairs treatment approaches result in generalization of treated sounds in a targeted pattern to untrained words containing the treated sounds and to untreated sounds/sound contexts in the same phonological pattern? Probes were administered at pre- and posttest and every 2 weeks by eliciting three untrained words and three words with untreated 
Table 6

Summary and Analysis of APP-R Results

Percentage of occurrence

Change

Pattern deviations

$\overline{\text { Pretest Midway Posttest }}$

Amounta Percent $^{b}$

\begin{tabular}{lrrrrr}
\hline Syllable reduction & 21 & 5 & 5 & -16 & $76 \%$ \\
Prevocalic singletons & 20 & 11 & 9 & -11 & $55 \%$ \\
Postrocalic singletons & 74 & 61 & 68 & -6 & $8 \%$ \\
Consonant sequences & 105 & 100 & 90 & -15 & $14 \%$ \\
Stridents & 65 & 63 & 49 & -16 & $25 \%$ \\
Velars & 86 & 95 & 100 & +14 & $-16 \%$ \\
Liquid /// & 82 & 82 & 82 & 0 & $0 \%$ \\
Liquid /r/ & 52 & 43 & 43 & -9 & $17 \%$ \\
Nasals & 26 & 21 & 32 & +6 & $-23 \%$ \\
Glides & 90 & 30 & 20 & -70 & $78 \%$ \\
Average deviations & 62 & 51 & 50 & -12 & $19 \%$ \\
Severity interval & profound & severe & severe & & \\
\hline
\end{tabular}

Note. Pre- and posttest results were compared to determine the amount of change and the percent of change. aDecrease (-) indicates improvement in percentage of occurrence. bDecrease $(-)$ indicates increase in percentage of occurrence of deviations and increase indicates improvement. 
sounds/sound contexts for each targeted pattern (see Appendix B for a list of probes). Results of generalization probes are displayed in Table 7.

\section{Probes for Phonological Cycling}

The phonological cycling approach was used for liquid /// and consonant sequences/stridents in both Cycle I and Cycle II. Probes indicated that the subject generalized consonant sequences/stridents, but not liquid $/ \%$.

Liquid $/ /$. Pretest scores for $/ / /$ were $0 \%$ for untrained words and untreated sounds. Subsequent probing showed that no generalization occurred in liquid /I/. Some improvement was noted after Cycle I, but the percentages dropped back to zero after Cycle II.

Consonant sequences/stridents. Pretest scores for consonant sequences/stridents were also $0 \%$ for untrained words and untreated sounds. Subsequent probing showed that no generalization occurred in the untreated initial sound /sw/. Generalization to untrained words occurred after training in Cycle I (30\%), dropped slightly after 2 weeks (20\%), and improved sharply after Cycle II (60\%) where it remained through the posttest.

\section{Probes for Minimal Pairs}

Minimal pairs were used to treat postvocalic consonants for 2 weeks and liquid $/ r /$ for 2 weeks. Probes indicated that the subject generalized both deviant patterns.

Postvocalic Singletons. Pretest scores for postvocalic singletons were $0 \%$ for untrained words and $30 \%$ for untreated sounds. Subsequent probing 
Table 7

Results of Probing for Generalization

Percent of probe words produced correctly

Deviation Pretest Cycle I Minimal pairsa Cycle ll Minimal pairsb Posttest

Liquid /II

Words

$0 \% \quad 10 \%$

$15 \%$

$0 \%$

$0 \% \quad 0 \%$

Sounds

$0 \% \quad 0 \%$

$0 \%$

$0 \%$

$0 \% \quad 0 \%$

Consonant sequences/stridents

Words

$0 \% \quad 30 \%$

$20 \%$

$60 \%$

$60 \% \quad 60 \%$

Sounds

$0 \%$

$0 \%$

$0 \%$

$0 \%$

$0 \% \quad 0 \%$

Postvocalic consonants

Words

$0 \% \quad 0 \%$

$0 \%$

$0 \%$

$0 \% \quad 0 \%$

Sounds

$$
30 \%
$$

$40 \%$

$60 \%$

$75 \%$

$80 \% \quad 80 \%$

Liquid / $/$ /

Words

$50 \%$

$50 \%$

$60 \%$

$50 \%$

$75 \% \quad 75 \%$

Sounds

$50 \%$

$50 \%$

$50 \%$

$50 \%$

$60 \% \quad 70 \%$

Note. Words are untrained words. Sounds are untreated sounds/sound contexts. All probe words were elicited at pretest, at the end of each of the four treatment approaches, and at posttest. apostvocalic consonants treatment. bLiquid /r/ treatment. 
showed that no generalization occurred in the untrained words. Percentages for the untreated sound, final $/ \mathrm{n} /$, gradually improved from a pretest score of $30 \%$ up to $80 \%$ at posttest, indicating that the subject generalized postvocalic consonant untreated sounds.

Liquid $/ r /$. Pretest scores for $/ r /$ were $50 \%$ for both untrained words and untreated sounds. Before the subject was treated for liquid $/ r$, probes indicated a temporary improvement in untrained words (60\%). After treatment for liquid $/ r /$, the subject improved to $75 \%$ where she remained at posttest. Improvement in the untreated sound (medial / $/$ ) was not evident until after liquid $/ \mathrm{r} /$ training $(60 \%)$ and another increase at posttest $(70 \%)$. These posttest results ( $75 \%$ for untrained words and $70 \%$ for untreated sounds) indicated generalization for this subject in liquid $/ r /$.

\section{Discussion}

Overall, the subject in this study demonstrated improvement in her phonological system over the course of treatment for targeted phonological patterns as indicated by pre- and posttest scores of the APP-R. Generalization probes indicated some generalization occurred to untrained words and untreated sounds/sound contexts in the same phonological pattern. In discussing the results of this study, the two hypotheses, treatment effectiveness and treatment generalization, are addressed first followed by discussion of experimental control. 


\section{Treatment Effectiveness}

Multiple baseline measurements for this study indicate that both treatment methods, phonological cycling and minimal pairs, were effective for this subject. Improvement may have been affected by the parental support offered to this subject at home. These results support those of Tyler et al. (1987), whose study compared the same two phonologically-based treatment approaches and included a home program. Tyler et al. (1987) found that both procedures were effective in facilitating the suppression of the subjects' treated phonological deviations.

Another comparative study of the two approaches included a home program, but very little change was reported in similar targeted phonological patterns (liquid $/ / /$, liquid $/ r /$, consonant sequences/stridents, and velars) for a 4year, 6-month old male (Royer, 1995). The reason for this discrepancy is not clear, although it could be maturation of the subject in the present study even though she was one year younger than Royer's subject. Maturation of a normal phonological system is not dependent on chronological age, but on the readiness of the child's system to change. The parental support may have been less involved than the support given in this study.

\section{Effectiveness of the Phonological Cycling Approach}

Targeted patterns treated with the cycling approach in this study improved for consonant sequences/stridents while liquid ///indicated no improvement. Based on these results, it can be said that for this subject, 
phonological cycling was effective for consonant sequences/stridents, but not for liquid //. Reasons for this inconsistency are uncertain although it is possible to speculate why improvements were noted for consonant sequences/stridents and not for liquid /// by examining normal phonological development and individual differences.

Liquid //. Liquid /// may not have improved because it is a later developing pattern although Hodson and Paden (1991) recommended including liquid $/ / /$ in early cycles. There may have been insufficient treatment for this later-developing pattern considering that only 2 weeks of treatment for $/ / /$ were completed. A treatment cycle, as defined by Hodson and Paden, is considerably longer than 2 weeks, often approaching 9 to 15 weeks in length. More time in the cycle allows children time to acquire their phonological system gradually. For the purposes of this study, however, only 8 weeks elapsed throughout this study not allowing time for the subject to internalize newly learned patterns or to return to original target patterns months later.

These speculations are supported by Royer's (1995) subject whose liquid /// deviation scores on the APP-R remained at $100 \%$ throughout the 8 week study. Support is also offered by Gordon-Brannan et al. (1992) whose subject's pretest APP-R score for liquid /// (100\%) improved significantly at posttest ( $9 \%$ ), but only after 2 years of remediation suggesting that liquid $/ /$ took time to emerge for this subject. Another factor that may have assisted GordonBrannan et al.'s subject was arranging remediation once a week instead of meeting 3 days a week as in this current study and in Royer's (1995) study. 
Weekly meetings give subjects more overall time to improve their deviant patterns.

Consonant sequences/stridents. Consonant sequences/stridents may have improved because they are earlier developing patterns. Targeting these two patterns (consonant sequences and stridents) as one pattern (consonant sequences/stridents) facilitates emergence, especially when the subject substitutes stops for stridents as was the case in this study (Hodson \& Paden, 1991). Therefore, this pattern may have had an advantage over liquid /// because it is earlier developing and is easier to facilitate.

Tyler et al. (1987) also reported improvement for one subject when targeting consonant sequence/stridents using the cycling approach. Over a 3week period of training for initial/sn/ and/sp/, their $4: 1$ subject improved from a pretest deficiency score of $98 \%$ to $67 \%$ after the 3-week treatment evoking the possibility that this pattern was easily facilitated for this subject. This pattern was not facilitated, however, for Royer's (1995) subject whose posttest results $(93 \% / 60 \%)$ were worse than at pretest $(90 \% / 58 \%)$.

\section{Effectiveness of the Minimal Pairs Approach}

Targeted patterns treated with the minimal pairs approach in this study improved for both postvocalic singletons and liquid / $/$ / although the improvement in postvocalic singletons was less than liquid /r/. Based on these results, it can be said that for this subject, minimal pairs was effective for both patterns, but was more effective for liquid $/ r /$ than for postvocalic singletons. Unlike the 
cycling approach, it is more difficult to speculate why liquid $/ r /$ improved more than postvocalic singletons when this is opposite from expected results according to normal phonological development where postvocalic singletons usually emerge in children's utterances before liquid /r/. This exception from normal development, where some later sounds are produced before some earlier sounds, has been referred to as chronological mismatch (Hodson \& Paden, 1991).

Postvocalic Singletons. As an early developing pattern, postvocalic singletons were expected to improve as was evident with consonant sequence/stridents. Although postvocalic singletons did improve for this subject, the improvement was less than for the later developing liquid $/ r /$ that was treated with a minimal pairs approach. This could be due to the higher pretest scores of postvocalic singletons (74\%) as compared to liquid $/ r /(52 \%)$ suggesting that postvocalic singletons were more deviant for this subject, despite normal phonological developmental studies stating that postvocalic singletons usually resolve before liquid $/ r /$. This higher score suggests remediation will take more than time to develop, certainly more than the 6 sessions allowed in this study. In fact, it took $\mathbf{4}$ sessions for the subject to complete the imitation level leaving only 2 sessions to pass criterion for independent naming. The design of minimal pairs, to continue at a level until criterion is reached, may have been a detrimental factor for this subject's final consonant deletions.

These findings were compatible with those of Weiner (1981) though his 2 
subjects were considerably more successful in remediating deviant postvocalic singletons during minimal pairs treatment. Subject $A$, age 4:10, demonstrated final consonant deletion at pretest in $95 \%$ of his responses that decreased to $10 \%$ after 6 sessions. Pretest scores for subject B, $4: 4$, indicated $100 \%$ final consonant deletion which dropped to $0 \%$ after 14 sessions. For these subjects, minimal pairs treatment was effective in treating postvocalic consonants, although it should be noted that the subjects were older than the subject for this study and may have been more emotionally mature to accept and change their deviant patterns. The subject for this current study did not appear to hear the difference between the minimal word pairs in her own productions.

Liquid /rl. As a later developing pattern, liquid $/ r /$ was not expected to improve significantly especially when compared to the early developing postvocalic singletons. It may be important to note that liquid /r/ was already emerging in the subject's phonological system as was evidenced in her pretest scores and may have improved without treatment. The subject immediately imitated a liquid $/ r /$ word and could hear the difference in her own productions offering more support to its emergence into her phonological system.

These speculations support the improvement in liquid $/ r$ / for this subject, but do not explain why the pattern was emerging before other earlier developing patterns. It could be attributed to individual differences in phonological development. The subject in Gordon-Brannan et al. (1992) was more typical for phonologically delayed children. His pretest scores for liquid $/ \mathrm{r} /$ were $100 \%$ and decreased to $81 \%$ after 2 years of treatment. 


\section{Treatment Generalization}

In support of phonological remediation, it was expected that generalization would occur to all untrained words and untreated sounds/sound contexts in the same phonological pattern. In this study, generalization probes indicate that some generalization occurred for this subject in both treatment methods, phonological cycling and minimal pairs. Specifically, probes indicate that for this subject, generalization occurred in three of the four targeted patterns: consonant sequences/stridents, postvocalic consonants, and liquid /r/. There was no evidence of generalization for liquid //. Consonant sequences/stridents generalized to untrained words but not sounds/sound contexts, while postvocalic consonants showed the opposite pattern by generalizing to untrained sounds/sound contexts and not untrained words. Liquid $/ r$ / successfully generalized to both untrained words and untreated sounds/sound contexts. These results indicate that for this subject, generalization did not occur in all expected contexts. Given time for these newly learned patterns to be incorporated into the phonological system, however, generalization may have occurred. The time line of this study of 8 weeks, may have prevented the subject from fully benefiting from phonological remediation.

Another comparative study reported generalization occurred for untreated sounds in all target patterns for 4 subjects (Tyler et al., 1987). The reason for successful generalization for Tyler et al. could be because each subject in their study received treatment over a longer time. Also, they did not use an 
alternating treatment design. Each subject received either minimal pairs or phonological cycling treatment instead of alternating treatment on the same subject as occurred in this current study.

Royer's (1995) study, although similar in design, does not support the results of this current study. While Royer's subject also displayed generalization for consonant sequences/stridents after treatment, no other target pattern showed generalization to untrained words or untreated sounds/sound contexts in the same phonological pattern. Also, the subject in Royer's study showed minimal improvement in his phonological deviancy score on the APP-R from pretest $(58 \%)$ to posttest $(57 \%)$ while the subject for this study made clinically significant improvements (from $62 \%$ to $50 \%$ ). Possible reasons for the different results between the two studies include individual and maturation differences.

\section{Generalization in Phonological Cycling}

Generalization probes for target patterns treated with phonological cycling indicated considerable generalization to untrained words for consonant sequences/stridents while none occurred in the untreated initial sound/sw/. This sound combination proved difficult for this subject which may reflect her initial problems with glides. Perhaps generalization would have occurred on consonant sequences not probed.

No generalization occurred for liquid $/ / /$ for this subject in untrained words or untreated sound/sound contexts, accurately reflecting her APP-R scores that 
indicated no improvement at posttest. For this subject, liquid /// was stimulable in CV words/sounds (e.g., lie,) but she was not successful with CVC words (e.g., lion).

\section{Generalization in Minimal Pairs}

Generalization probes for target patterns treated with minimal pairs indicated the subject did generalize postvocalic consonants to untrained sounds/sound contexts but not to untrained words. The untreated sound, final $/ n /$, was easily facilitated because the nasal $/ n$ / was easy for this client to produce in all positions. This successful generalization in untreated sounds may have helped the percentage of improvement in posttest APP-R scores (8\%) for postvocalic singletons. Exhibiting no generalization in the untrained words may have been due to the subject's difficulty in hearing the difference between minimal word pairs in her own productions. This continued difficulty corresponds with her postvocalic singletons posttest scores (68\%) indicating a need to continue remediation.

Generalization for this subject was most successful with liquid / $r$ / where generalization occurred in both untrained words and untreated sound contexts. This success is reflected in the percentage of improvement (17\%) for liquid $/ r /$ at posttest and supports the evidence of her initial readiness to incorporate the sound into her phonological system.

These results do not agree with the findings of Saben and Ingham's (1991) study whose 2 subjects did not generalize minimal pair treatment to 
untrained words nor to untreated sound/sound contexts. This could be because in their study, they attempted to eliminate traditional cues of articulatory placement during treatment. By omitting the use of imitation and phonetic placement cues during treatment, the authors wanted to isolate the linguistic aspect of minimal pairs to examine remediation success without the direct motoric training. When the subjects were unable to produce the contrasting pairs spontaneously, motor-perceptual assistance was provided, thus, indicating the importance of imitation for these subjects. Despite their success in meeting all the criterion, the subjects did not generalize. One possible reason is the authors did not begin the production level with letting the child be the "teacher" which gives the child immediate feedback on the results of omitting the final consonant (e.g., when the listener points to the wrong picture). Also, the subjects needed a significant number of trials (70-220) to pass the comprehension level. The authors chose to continue at this level instead of discarding words not in the subjects' linguistic vocabulary. In contrast to Saben and Ingham (1991), a study by Weiner (1981) reported successful generalization to untrained words for 2 subjects over a considerably shorter time. Weiner's (1981) success may be due to his simpler design and purpose, using the "child as the teacher" step, and using words meaningful to the subjects.

\section{Experimental Control}

Baseline measurements demonstrate experimental (behavioral) control if 
all target patterns improve while untreated patterns remain at baseline as compared to pretest results. Some experimental control is evident in this study within the target patterns where three of the four targeted patterns improved. (See Table 6 for the percent of change between the pre- and posttest results.) On the other hand, experimental control was not established for the untreated patterns since neither of the two control patterns remained at baseline. Therefore, the control patterns, glides and velars, did not establish behavioral control in this study.

One can speculate as to the reasons that the control patterns did not remain at baseline by examining normal phonological development, individual differences, and considering the design of the study. Glides may have improved because they are early developing. Velars, on the other hand, develop in the middle and generally emerge later than glides. For this subject, velar deviations increased at posttest as compared to pretest. This decline may be connected to the fact that velars were not stimulable for this subject.

The improvement in the glide control pattern for this subject may also be explained by the theory behind phonological treatment, that is, the phonological approach to treatment facilitates the phonological systems as a whole rather than just targeting specific patterns (Hodson \& Paden, 1991). Perhaps the improvement reflects this subject's general improvement in improving her phonological system.

Despite the subject's improvement, the control variables in this study were not under experimental control. This may suggest that multiple baselines 
across behaviors with an alternating treatment design on one subject may not be the best research design for examining treatment efficacy. Without experimental control in a single-subject design, extraneous variables cannot be ruled out as factors in the subject's improvement. Multiple baselines across subjects without alternating treatment may be a better choice.

\section{Summary}

Overall, both treatment methods were shown to be be effective for improving some of the treated phonological patterns for this subject as was evident in her posttest APP-R scores though neither method was clinically more effective than the other. Probe words indicated generalization occurred to untrained words and untreated sounds/sound contexts in some phonological patterns but not in all expected contexts. Control patterns did not show experimental control. Although all target patterns remain deviant and need continued remediation, the subject's phonological system as a whole improved during the course of treatment.

In considering the results of this study, it is important to account for factors affecting these results including the individual subject, extraneous variables, and time spent in remediation. Remediation results were affected by the subject's individual phonological development. Maturation of the subject also could have affected results, especially since control was not established to rule out extraneous variables. In other words, improvement may have occurred without intervention due to subject's maturation, elapsed time, and/or nonclinical 
environments. Time variables also affected the results of this study.

Remediation was designed to occur within 8 weeks instead of over the usual

course of treatment that would continue until the APP-R scores were less than $40 \%$. Meeting 3 times per week rather than once a week did not allow the subject enough time in between sessions to internalize newly learned patterns. 


\section{CHAPTER V \\ SUMMARY AND IMPLICATIONS}

\section{Summary}

Choosing an effective and efficient phonological treatment approach is an important decision for clinicians when treating children with phonological deviations. Current research supports the effectiveness of phonological treatment, but few studies have compared two approaches. More comparative studies are essential to support clinical intervention for children who are highly unintelligible.

This single-subject study was designed to compare the effectiveness of two phonologically-based treatment approaches in facilitating an intelligible speech production system for one highly unintelligible preschool female. Multiple baselines across behaviors with an alternating treatment design were used in this descriptive study. This study sought to answer the following questions: (a) Is there a clinically significant difference between the effectiveness of the cycling approach and the minimal pairs approach in treating a child with phonological disorders? and (b) Do the phonological cycling and/or the minimal pairs treatment approaches result in generalization of treated 
sounds in a targeted pattern to untrained words containing the treated sounds and to untreated sounds/sound contexts in the same phonological pattern?

Using the phonological assessment instrument, the APP-R in conjunction with the CAPD, four phonological deviations were chosen for phonological remediation. Two deviations were assigned to the phonological cycling approach (Hodson \& Paden, 1991) and two to the minimal pairs approach (Blache, 1989; Fokes, 1982). Remediation alternated between the two approaches every 6 sessions, beginning with the cycling approach, for a total of 24 sessions. Treated sounds from each targeted deviation were taught and reassessed using the APP-R to compare treatment effectiveness. To examine generalization of targeted phonological patterns to phonemes in other contexts, periodic probes of treated sounds within untrained words and untreated sounds/sound contexts in the same pattern were administered.

Results of the CAPD indicate that both treatment methods were effective in improving some of the treated phonological deviations for this subject though neither method was more effective than the other. Probe words indicated generalization to untrained words and untreated sounds/sound contexts in some phonological patterns. These findings support the phonologically-based theory of remediation: the goal of phonological treatment is developing a whole phonological system, rather than perfecting targeted deviations 
Implications

\section{Clinical Implications}

In this study, both phonologically-based treatment approaches were effective in improving this subject's phonological deviations. However, from a clinical perspective, this researcher prefers the cycling approach, especially for young children with highly unintelligible speech. In general, the cycling approach is less structured and more natural (i.e., closely approximates normal phonological development) than the minimal pairs approach. Minimal pairs is structured by establishing a criterion for movement to the next level, thus creating a potentially frustrating situation for children when they must repeat the same words without success. The cycling approach eliminates the criterion and allows children to be successful during remediation. If they are not successful with a pattern or sound, the treatment schedule is revised by moving to a different pattern or sound. Also, in the minimal pairs approach, time spent on one pattern often lasts a long time, while the cycling approach limits the time spent on one pattern and returns to it later in a subsequent cycle.

In other instances, minimal pairs could be a more appropriate choice. For example, children who are not highly unintelligible and present with a small number of deviant patterns, the minimal pairs approach is efficient because of the concentrated time spent on one phonological pattern. Remediation is also more effective when children are mature enough to understand the implications of using the wrong words and can hear the difference in their own productions. 
Some children, regardless of age, perform better in a more structured environment. The minimal pairs may be a better choice for these children, especially if they respond well to visuals such as stickers that can be placed on a chart (e.g., a "ladder of success") for each success within the levels.

Before deciding between the two phonological intervention methods, all children need to be considered on an individual basis. Their personalities, learning styles, behavior, attention span, age, and maturity are important factors along with phonological severity. Some children may even benefit from a combination of the two approaches.

\section{Research Implications}

Single subject designs are appropriate for exploring treatment efficacy in phonological intervention. Based on the results of this study, there are several recommendations that researchers should consider when comparing the effectiveness of the phonological cycling and minimal pairs treatment approaches. To examine intersubject variability among subjects, the design of this study could be duplicated using other subjects. Parental support could also be explored to determine the effects of parental involvement and to monitor the time spent in the home environment on phonological homework assignments.

This study could be duplicated with one variable changed to examine variables affecting the results. Variations could include assigning the patterns to opposite treatment approaches, targeting consonant sequences and stridents as separate patterns, using more than three treated sounds, and choosing different 
treated sounds and/or untreated sounds/sound contexts. Variations of the subject could include subjects of different ages, hearing impaired subjects, and subjects with different levels of phonological severity. Variability among the subjects could then be analyzed.

The time line could be extended to increase the effectiveness of treatment and generalization results. For example, by allowing at least 16 weeks for remediation (instead of the 8 weeks used in this study), the subject would have more time to improve deviant patterns and develop a mature phonological system. An ideal study would not limit the remediation in terms of time, but instead in terms of a specific criteria, such as achieving less than $40 \%$ on all APP-R phonological patterns.

To rule out extraneous variables, a multiple baseline design across subjects, instead of across behaviors, may be a more appropriate choice for future comparative studies designed to support clinical efficacy. If the subjects' targeted patterns change only when treated and their untreated patterns remain at baseline, there is strong evidence of experimental control. Each subject could be treated with one approach, similar to the Tyler et al. (1987) study, rather than alternating treatment on one subject.

Treatment generalization in phonological intervention can also be explored using single subject designs. Results of this study point to several suggestions for researchers to consider in future studies. Generalization could be investigated in more depth by expanding the sounds/sound contexts probe lists. In this study, only one sound context was probed for each targeted pattern 
which provided minimal information. Another study could also elicit delayed imitation responses for probe words as in the study by Weiner (1981) instead of measuring unmodeled productions as was done in this study. Generalization could also be analyzed in conversational speech samples, rather than seeking specific probe words.

This study has made an important contribution for SLPs to consider when choosing between two phonological treatment approaches, but, it is critical for all SLPs to continue researching and comparing effective treatment methods. Most of the current research focuses on one treatment method. While these are important studies, more comparative studies are needed to add validity and efficacy to phonological intervention. 
References

Barlow, D. H., \& Hersen, M. (1984). Single case experimental designs. New York: Pergamon Press.

Blache, S. E. (1989). A distinctive-feature approach. In N. A. Creaghead, P. W. Newman, \& W. A. Secord (Eds.), Assessment and remediation of articulatory and phonological disorders (2nd ed., pp. 361-382). Columbus, $\mathrm{OH}$ : Merrill.

Blache, S. E., Parsons, C. L., \& Humphreys, J. M. (1981). A minimal word-pair model for teaching the linguistic significance of distinctive feature properties, Journal of Speech and Hearing Disorders, 46, 291-296.

Compton, A. (1970). Generative studies of children's phonological disorders. Journal of Speech and Hearing Disorders, 35, 315-339.

Connell, P. J., \& McReynolds, L. (1988). A clinical approach to treatment. In J. J. Lass, L. McReynolds, J. Northern, \& D. Yoder (Eds.), Handbook of speech-language pathology and audiology (pp. 1058-1073). Philadelphia: B. C. Decker.

Creaghead N. A. (1989). Linguistic approaches to treatment. In N. A. Creaghead, P. W. Newman, \& W. A. Secord (Eds.), Assessment and remediation of articulatory and phonological disorders (2nd ed., pp. 193-209). Columbus, $\mathrm{OH}$ : Merrill.

Elbert, M., \& Gierut, J. A. (1986). Handbook of clinical phonology approaches to assessment and treatment. San Diego, CA: College-Hill Press.

Fokes, J. (1982). Problems confronting the theorist and practitioner in child phonology. In M. Crary (Ed.), Phonological intervention (pp. 13-34). San Diego, CA: College-Hill Press.

Gordon-Brannan, M. E., Hodson, B. W., \& Wynne, M. K. (1992). 
Remediating unintelligible utterances of a child with a mild hearing loss.

American Journal of Speech-Language Pathology, 30, 28-38.

Hegde, M. N. (1987). Clinical research in communicative disorders.

Boston: College-Hill Press.

Hodson, B. W. (1980). The assessment of phonological processes.

Danville, IL: Interstate Press.

Hodson, B. W. (1982). Remediation of speech patterns associated with low levels of phonological performance. In M. Crary (Ed.), Phonological intervention (pp. 97-115). San Diego, CA: College-Hill Press.

Hodson, B. W. (1986). The assessment of phonological processes revised. Danville, IL: Interstate Press.

Hodson, B. W. (1992). Computer analysis of phonological deviations. Stonington, IL: PhonoComp software.

Hodson, B.W., \& Paden, E. P. (1991). Targeting intelligible speech (2nd ed.). San Diego, CA: College-Hill Press.

Ingram, D. (1982). The assessment of phonological disorders in children: The state of the art. In M. Crary (Ed.), Phonological intervention (pp. 1-12). San Diego, CA: College-Hill Press.

Ingram, D. (1989). Phonological disability in children (2nd ed.). San Diego, CA: Singular.

Kazdin, A. E. (1982). Single-case research designs. New York: Oxford Press.

McReynolds, L. V., \& Kearns, K. P. (1982). Single-subject experimental designs in communicative disorders. Baltimore: University Park Press.

McReynolds, L. V., \& Thompson, C. K. (1986). Flexibility of singlesubject experimental designs. Part l: Review of the basics of single-subject 
designs. Journal of Speech and Hearing Disorders, 51, 194-203.

Paul, R. (1995). Lanquage disorders from infancy through adolescence. St. Louis, MO: Mosby.

Royer, H. K. (1995). Clinical application of two phonological-based treatment approaches. Unpublished master's thesis, Portland State University, Portland, Oregon.

Saben, C. B., \& Ingham, J. C. (1991). The effects of minimal pairs treatment on speech-sound production of two children with phonologic disorders. Journal of Speech and Hearing Research, 33, 70-83.

Secord, W. A. (1989). Introduction. In N. A. Creaghead, P. W. Newman, \& W. A. Secord (Eds.), Assessment and remediation of articulatory and phonological disorders (2nd ed., pp. 1-6). Columbus, $\mathrm{OH}$ : Merrill.

Tyler, A . A., Edwards, M. L., \& Saxman, J. H. (1987). Clinical application of two phonologically based treatment procedures. Journal of Speech and Hearing Disorders, 52, 393-409.

Tyler, A. A., \& Sandoval, K. T. (1994). Preschoolers with phonological and language disorders: Treating different linguistic domains. Language, Speech, and Hearing Services in Schools, $25,215-234$.

Walsh, H. (1974). On certain practical inadequacies of distinctive feature systems. Journal of Speech and Hearing Disorders, 39, 32-43.

Weiner, F. F. (1981). Treatment of phonological disability using the method of meaningful minimal contrasts: Two case studies. Journal of Speech and Hearing Disorders, 46, 97-103. 
Weiss, C. E., Gordon, M. E., \& Lillywhite, H. S. (1987). Clinical management of articulatory and phonologic disorders (2nd ed.). Baltimore: Williams \& Wilkins.

Zimmerman, I. L., Steiner, V., \& Pond, R. (1992). Preschool Language Scale- 3. San Antonio, TX: Psychological Corporation. 
Appendix A

Informed Consent Form

I, agree that my child,

may take part in this research project on comparing phonological treatment approaches.

I understand that the study involves my child being tested for hearing and phonological disorder and will be treated for this disorder in the Portland State University Speech and Hearing Clinic by Katherine Kemper who will target the child's specific sound patterns that are unintelligible. Two different standard, well-established treatment approaches will be used over the next 8 weeks.

Games and art projects, chosen to match my child's interests and abilities will be used while my child practices saying words. My child will meet with Katherine 2 or 3 times a week as agreed by all parties.

I understand that, because of this study, my child may feel some initial anxiety due to the unfamiliar environment and periodic frustration when my child is unable to pronounce words correctly. I understand this is expected during routine speech therapy.

Katherine Kemper has told me that the purpose of this study is to compare two different treatment approaches that are both well-established for use in speech therapy to find if one is more beneficial.

My child may not receive any direct benefit from taking part in this study apart from the benefits normally derived from speech therapy. This study may also help in increasing knowledge for helping others in the future.

Katherine Kemper has offered to answer any questions I have about the study and what my child is expected to do. I may call her on the phone. I understand these sessions constitute the regular course of my child's therapy.

She has promised that all the information I give will be kept confidential to the extent permitted by law, and that my child's name and my name will be kept confidential.

I understand that my child does not have to take part in this study and that I may withdraw from this study at any time without affecting my relationship with Portland State University Speech and Hearing Clinic.

I have read and understand the foregoing information and agree to take part in this study.

Date: Signature:

If you have concerns or questions about this study, please contact the Chair of the Human Subjects Research Review Committee, Research and Sponsored Projects, 105 Neuberger Hall, Portland State University, (503) 725-3417. 
Appendix B

List of Training Words and Probe Words

\section{Liquid $/ / /$}

Training words

leaf

lip

laugh

lamb

love

balloon

yellow

smiling

belly

pillow

blue

blow

block

blanket

black

play

plant

plum

plate

plane
Untrained words Words for untreated sounds

lion

light

lie

flower

flag

flute

dolly

silly

jolly

blossom

blaze

blade

please

pliers

plenty

\section{Consonant Sequences/Stridents}

Training words

splash

spoon

spider

spin

spill

Untrained words Words for untreated sounds

spot

spy

spell swing

swim

sweater 
Training words

star

stop

stick

stamp

stone

smoke

smile

smell

small

smooth

snow

snake

snail

snore

sneeze

ants

hats

cats

nuts

boots

tops

hops

pops

naps

cups

Training words

boat/bow

hat/hay

nut/knee
Untrained words Words for untreated sounds

step

story

stand

smart

smock

smash

sniff

snuggle

snap

rabbits

sits

coats

mops

peeps

helps

\section{Postrocalic Consonants}

Untrained words Words for untreated sounds

light

sun

toot

man

goat

hen 
Training words

road/row

bead/bee

seed/see

home/hoe

boom/boo

mom/mow

Training words

rock/walk

rain/wind

run/watch

fair/foe

mare/may

tire/tie

train/wait

try/why

trail/wail
Untrained words Words for untreated sounds

hide

load

room

some

Liquid /r/

Untrained words Words for untreated sounds

rabbit

Mary

rug

turtle

tired

car

diaper

track

tree 